\title{
New approach in laser physics education
}

Gregory Altshuler, Nickolai Belashenkov, Andrey Okishev

Gregory B. Altshuler, Nickolai R. Belashenkov, Andrey V. Okishev, "New approach in laser physics education," Proc. SPIE 1603, Education in Optics, (1 March 1992); doi: 10.1117/12.57902

SPIE. Event: Education in Optics, 1991, Leningrad, Russian Federation 
New Approach in Laser Physics Education

Grigori.B.Altshuler, Nikolai.R.Belashenkov, Andrew V.Okishev Laser Center of St.Petersburg Institute for Fine Mechanics and Optics

\section{ABSTRACT}

In this paper the new approach in teaching of laser courses which was developed and used at St.Petersburg Institute for Fine Mechanics and Optics is described. In this approach practical work on investigation of laser beams, theory of lasers, nonlinear optics and applied spectroscopy combine with execution of $1 a b$ works on IBM PC-AT-286 compatible computers. Introduction of the developed technique into curricula of optical educational institutions will provide to intensify the educational process with increasing of the part of original work of students and also to realize as individual principle of education so as to train groups of students (3-4 persons) as prototype of future teams of scientists.

In the paper the perspectives of international co-operation in the field of teaching of general and special optical courses based on expirience of leading optical educational institutions are also considered.

\section{INTRODUCTION}

There are two types of laser courses in the curricula of Universities or optical Institutes:

- laser course for students will be specialists in lasers and laser optics and

- laser course as a special course for students who are 
1aser optics and

- laser course as a special course for students who are specialized in general optics. We think that each course on lasers may be divided in three main parts: (1) theoretical education, (2) training using a computer and (3) experimental work. Fundamentals of the first one which are common for all forms of training in lasers to our mind are the following:

- laser physics,

- laser optics,

- nonlinear optics.

We offer also to build the second and third parts on a modular principle, which allows to create easily a laser course for any type of high school. Using this approach one can create a course for training in lasers choosing some chapters from the theoretical part and expanding them by some computer and experimental lab works.

We've developed all above-listed parts of a laser course on the base of the computer Complex of Teaching Tools and Module Training Lab.

\section{COMPUTER COMPLEX OF TEACHING TOOLS}

The computer complex consists of the following tools.

\subsection{Computer textbook}

The computer textbook is a ramifide system of information supply for students. It includes:

- text of lessons with figures and animated pictures,

- computer demonstrations of principal phenomena and processes with the possibility of their modelling in various situations,

- reference information,

\subsection{Computer lab works}

Computer lab works are destinated to execute a specific 
indivisible task. They may be combined into more complicated tasks and into course works also.

The base computer lab works which were developed at our department are:

- analysis and synthesis of laser cavities,

- alignment of laser cavity,

- free-running operation mode of solid-state laser,

- actively Q-switched solid-state laser,

- saturable absorber,

- passively Q-switched solid-state laser,

- mode-locked solid-state laser,

- laser amplifier,

- second harmonic generation,

- Raman conversion of laser radiation,

- tunable dye laser,

- transformation of laser beams in optical systems.

\subsection{System of current and final cheking of the progress of} students

The system includes multistage checking tests which must be passed during the current term (e.g. access to execution of $1 a b$ work, defense of results of work etc.) and final examination.

\subsection{Data base on lasers and laser optics}

Data base includes comprehensive information on parameters of laser and optical elements and devices - refraction indices, gain and absorption cross sections, laser wavelengths, spectral sensitivities of photocathodes etc.

\section{MODULE TRAINING LAB}

Module Training Lab consists of the following units:

- honeycomb optical table $80 \times 200 \mathrm{~cm}$,

- He-Ne laser 
- two pump chambers with YAG:Nd or YAP:Nd active elements,

- two power supplies $(100 \mathrm{~J})$,

- cooling unit,

- energy/power meter,

- optical set (dielectric mirrors, prisms, lenses, dye cell, nonlinear crystals, polarizers, fresnel rhombs, retardation plates, filters, photodiodes etc.),

- set of optical mounts and positioners.

This composition provides to realize a lot of demonstrations and lab works on course of general optics, laser physics and nonlinear optics. We've developed the set of practical lab works such as:

- laser cavity alignment,

- free-running generation,

- Q-switched pulsed solid-state laser,

- mode-locked pulsed solid-state laser,

- amplification of laser radiation,

- second harmonic generation,

- tunable pulsed dye-laser,

- 1aser beam optics,

- coherence of laser radiation,

- polarization optics.

\section{TECHNIQUE OF TRAINING}

In the case of training of students of general optics specializations the technique of training is similar to traditional one: theoretical chapters are combined with lab practical work. Using of computers comes to demonstrations imitating optical processes and to illustrations of theoretical chapters of the course. For most we11-trained students of general optics specializations the curriculum foresees the execution of computer lab works according to primitive tasks. Practical work of students takes place on the module training laboratory, 
experimental set-ups are assembled and aligned by technical personel of the department and students get practical knowledge during the execution of lab work.

students - future specialists in lasers and laser optics have much more enhanced and intensified curriculum. Experimental training combines computer and practical lab works in complete volume. The execution of computer lab works is strictly individual and precedes as a rule practical work. Corresponding to results got after theoretical and computer chapters the groups of 3-4 students for practical work are formed. The group gets in its disposal all equipment of module training laboratory, assemblies and aligns optical schemes according to lab tasks, executes necessary measurements and calibrations, investigates physical processes. After the end of the course the majority of these groups become the real teams of scientists able to solve complicated scientific problems.

\section{CONCLUSION}

Last years the optics as a chapter of science and technics determines trends and temps of technical progress of developed industrial countries. It leads from the one side to increasing of demand of high-skilled optical specialists and from the another one the broadening of the role of optics in the real 1 ife causes the sharp differentiation of training levels on various specializations in universities and optical institutions. In this situation separated department neither maybe an university can't provide training of specialists on all specializations of modern optics.

The new technology of teaching laser courses developed in St.Petersburg Institute for Fine Mechanics and Optics based on combination of theoretical, practical and computer training can be prototype for developing of curricula and programs of the optical courses as a whole. Advantages of the technology are: 
- The possibility of training specialists in groups imitating teams of scientists. For these groups the technology allows to intensify training process by separating of general questions of courses for individual study using computer and technical teaching tools and to train instead of them special questions.

- The possibility of training specialists of different qualification on the unificated equipment.

- The possibility of distribution and exchange of components of the technology between leading centers of training specialists in optics all over the world. 